\title{
Communication needs and food allergy: an analysis of stakeholder views
}

\author{
Susan Miles ${ }^{1}$, Rene Crevel ${ }^{2}$, George Chryssochoidis ${ }^{3}$, Lynn Frewer ${ }^{*}$, \\ Kate Grimshaw ${ }^{4}$ Alicia Guidonet Riera ${ }^{5}$, Hazel Gowland, \\ RebeccaKnibb ${ }^{7}$, Priska Koch ${ }^{8}$, Charlotte Madson ${ }^{9}$, Clare Mills ${ }^{10}$, \\ Susanna Palkonen ${ }^{11}$, Sylvia Pfaff ${ }^{2}$, Romana Roccaldo ${ }^{13}$, \\ Joachim Scholderer ${ }^{14}$, Oydis Ueland ${ }^{15}$, Erkka Valovirta ${ }^{16}$ and \\ Wim Verbeke ${ }^{17}$
}

\begin{abstract}
At present, the most useful approaches to communicating information about food allergy to different stakeholder groups are not understood. Stakeholders include allergic consumers, their carers, health professionals, public authorities (regulators and compliance authorities), retailers, manufacturers, caterers and the general public. Communication needs are reviewed both generally and specifically from the perspectives of different stakeholders. A stakeholder consultation was conducted to solicit the views of different stakeholders regarding what information is required. This indicated some common needs regarding, for example, causes and symptomology of food allergy. In addition, some specific information needs for different stakeholders were also identified. The industrial sector requires more information about clear guidelines for labelling practices, whereas the allergic consumers and health professionals require more information about symptomology, treatment and prevention. Regulators specifically need information from risk assessors regarding issues key to the implementation of an effective regulatory framework. This may need to be at a more detailed level of technicality than that required by other stakeholders (for example, consumers). The results therefore suggest that targeted information strategies may be the most resource-efficient way to communicate effectively to different stakeholders about food allergy. However, those information channels which are best suited to specific stakeholder needs remain to be established and exploited.

Keywords: food allergy; communication; stakeholders

\footnotetext{
${ }^{1}$ University of East Anglia, United Kingdom. Work conducted whilst this author was at the Institute of Food Research, Norwich, UK. ${ }^{2}$ SEAC, Unilever, Sharnbrook, UK. ${ }^{3}$ University of Athens, Greece. ${ }^{4}$ University of Southampton, United Kingdom. ${ }^{5}$ University of Barcelona, Spain. ${ }^{6}$ Anaphylaxis Campaign, United Kingdom. ${ }^{7}$ University of Derby, United Kingdom. ${ }^{8}$ Swiss Quality Testing Services, Switzerland. ${ }^{9}$ Danish Veterinary and Food Administration, Denmark. ${ }^{10}$ Institute of Food Research, Norwich, UK. ${ }^{11}$ Allergia, Helsinki, Finland. ${ }^{12}$ The International Retail Network, Germany. ${ }^{13}$ INRAN, Rome, Italy. ${ }^{14}$ Centre for Market Surveillance, Research and Strategy for the Food Sector, Denmark.

${ }^{15}$ MATFORSK, Norway. ${ }^{16}$ European Federation of Allergy and Airways Diseases Patients' Associations, EFA, Brussels, Belgium. ${ }^{17}$ University of Ghent, Belgium

* Corresponding author: Wageningen UR, Marketing and Consumer Behaviour Group, Hollandseweg 1, 6706 KN Wageningen, The Netherlands. E-mail: Lynn.Frewer@wur.nl
} 


\section{Introduction}

At present, the most useful approaches to communicating information about food allergy to different stakeholder groups are not understood. The purpose of the research presented in this paper is to define the most important issues regarding effective communication and food allergies, to understand the barriers to developing effective communication about food allergy, and to identify potential differences (e.g. between different stakeholder groups) in communication needs.

The paper aims to take due account of the diversity in European populations regarding the prevalence, incidence, severity and causality of food allergy. It has been developed in conjunction with the InformAll partnership to ensure it is of direct relevance to risk regulators, public authorities, the food industry, health workers and patient groups regarding effective communication about food-allergy issues. Allergic consumers, their carers and families were not specifically targeted as part of the analysis, although understanding the information needs of these individuals might usefully be a focus of future research activity. The results will be used to develop recommendations for communicating food-allergy information which aim to be of direct relevance to different end-users, including allergic consumers, health professionals, industry and regulators, public authorities, and which take due account of potential differences in information needs between these different stakeholder groups. The results will provide the basis for the development of an effective and useful communication strategy about food-allergy issues targeted at all end-users.

\section{Communication and food allergy}

Various communication issues can be identified which are salient to the topic of food allergy. The first relates to developing an effective communication mechanism with food-allergy sufferers, who are likely to have very specific individual and pragmatic information needs. The second involves communication with other relevant individuals and institutions, such as health professionals, the food industry and catering sector, and risk regulators and managers, each of whom may have different information requirements. As an example, the communication link between risk assessors and risk decision-makers demonstrates a specific situation where it is important to deliver appropriate information of direct relevance to risk-management issues (Frewer and Salter in press). There is, of course, also the question of provision of information to the population in general, who do not suffer from allergic conditions themselves, or who are not exposed to the issues through the experiences of family members. These individuals may need to be aware of the potential impact of food allergy and how to handle food preparation under circumstances where there is potential for allergic individuals to consume allergenic ingredients with adverse consequences. This may include, for example, situations when a non-allergic consumer is preparing food for distribution at social and community events such as fairs and fetes, birthday parties for children, and so forth. In the case of elderly persons, the importance of IgE-mediated allergy decreases with age; nevertheless, communication with elderly people is a specific situation that requires attention and is likely to increase in importance as the current generation of allergy sufferers ages.

When developing communication strategies, the question of food intolerance must also be considered. Given that the symptomology is commonly less severe and less well-defined than food allergy, there is some evidence of over-reporting of its incidence (Sloan and Powers 1986; Knibb et al. 1999a). An additional communication 
issue therefore, is avoiding the amplification of perceptions of illness associated with food intolerance. It would be highly problematic if people were encouraged to believe they were suffering from food intolerance, or even food allergy, when, in fact, their symptoms were attributable to some other medical cause, particularly under circumstances where appropriate medical treatments exist for the condition.

For these reasons, it is important to develop best practice in communication to facilitate optimal outcomes in terms of human health, which takes into account differences in information needs between different end-users. To date, there has been no systematic analysis of what the needs of these different stakeholders actually are.

\section{Impact of food allergy on quality of life}

It has been well established that allergy can have a profoundly negative impact on quality of life, extending beyond the immediate clinical effects of the individuals' allergic condition (Fernández-Rivas and Miles 2004). Food allergy is occasionally fatal (as it may be in the case of anaphylaxis), but more frequently, dietary restrictions may compromise social activities such as dining out or attending social functions (Knibb et al. 2000). Food allergy affects more than 6\% of children, and 1-2\% of the adult population (Anderson 1991; Bock and Sampson 1994; Sampson 2001); communication related to food-allergic children may therefore be a particularly important issue.

Food allergy has been found to exert a significant impact on the perception of general health of affected children, as well as an emotional impact on the parents and limitation of family activities (Sicherer, Noone and Muñoz-Furlong 2001). Children may also experience learning impairment, problems with peer-group socialization, anxiety and family dysfunction (Meltzer 2001). Primeau et al. (2000) found that families of peanut-allergic children experience significantly more disruption in their familial and social interactions than in families of a child with chronic rheumatologic disease. They suggest that this finding may be due to the constant risk of sudden death from anaphylactic reaction in the peanut-allergy group, leading to parental restriction of activities. Affected adults may also experience negative impacts on quality of life, including restricted leisure activities, loss of working time or days, impaired social functioning and psychological distress (Knibb et al. 1999a; Knibb et al. 2000).

\section{Communication with the allergic population}

Four groups of people are of immediate concern, when communicating information about food allergy: children, adolescents, adults and the parents of food-allergic children. Each group has individual needs and concerns, which poses challenges for effective communication.

Prevalence of food allergy is highest in young children (Sampson 2001), yet very little is known about the attitudes of food-allergic children to both food allergy generally and to their condition specifically, and little attention has been paid to the most effective methods of communication for this group. Research in this area is sorely needed. There has been a greater focus on the parents of children with food allergy (although again the literature is very sparse in this area). Research has shown that the method of communication and the source of that information can have an effect on the psychological distress of parents. For example, large amounts of information from dieticians can be overwhelming for parents and result in higher 
levels of perceived stress, as can information given merely in the form of leaflets with little explanation (Semper and Knibb in press).

It has also been found that parents often get their general knowledge about food allergy from media sources (such as television, radio, newspapers, magazines and the internet) or from family and friends (Knibb 2003). Given that many parents selfdiagnose and self-treat allergy in their children (Eggesbo, Botten and Stigum 2001; Young et al. 1994) this could have potentially serious consequences for the safety and health of their children, whether they have clinically confirmed food allergy or not. Therefore, the methods of communication and how that information is given and by whom, need careful consideration and further study.

Adolescents and young adults are the groups most at risk from severe food-allergy reactions (Bock, Muñoz-Furlong and Sampson 2001; Gowland 2002; Pumphrey 2000). Hourihane (2001a) has commented that there are additional difficulties in developing communication about food avoidance for these individuals for whom "risk-taking behaviour and ignoring advice from figures of authority are features of developing independence". This may indicate the need for specifically segmented communication approaches tailored to this differentially vulnerable group.

Finally, adults with food allergy must also be considered in the context of communication effectiveness. The communication needs of a person who has suffered from allergy all of his/her life may be very different from those of someone who has just recently been diagnosed. In addition, people with perceived food intolerance and who are self-diagnosed, need useful, accurate and trustworthy information about getting a clinical diagnosis or seeking further information about their symptoms (Booth and Knibb 2000).

There is a large body of evidence to show that effective patient-doctor communication can have an important impact on patient compliance to treatment (Ong et al. 1995), and on effective change of lifestyle and behaviour (Arborelius 1996; Golin, DiMatteo and Gelberg 1996). At time of writing, there is little research performed in this area focusing on food allergy, although some has focused on allergic rhinitis (e.g. Gani et al. 2001) and food-allergic patient compliance and patient-doctor communication (Eigenmann and Zamora 2002). This is also an area that merits further investigation. An improvement in communication between the medical profession, in primary care and in the hospital setting, and those who suffer from food allergies and their families may help to improve management of food allergy.

\section{Communication with the population in general}

Approximately one in five people in the UK, as well as in other industrialized countries such as the USA, believe that they are allergic or at least sensitive to specific foods. In contrast, the medically confirmed level of food allergy (in adults) is variously estimated at between 1 and 3.5\% (Young et al. 1994; Woods et al. 2002). Perceived food intolerance frequently results in self-treatment (in terms of dietary alteration) rather than seeking out medical advice (Young et al. 1994; Brugman et al. 1998; Eggesbo, Botten and Stigum 2001). This may be due to the restricted availability of medical treatment in some geographical locations and health-care systems, or possibly may be attributed to people's desire to retain control over their lives. This means that a large number of people may be modifying their diets, and that of their families, unnecessarily. Such dietary modification will probably be 
inconvenient and expensive, and can have an adverse impact on the nutritional status of food-allergic consumers and their families.

Best practice in developing a communication strategy should therefore address the issue of 'self-diagnosis and management' to ensure that those individuals who believe that they need treatment seek medical attention and do not misdiagnose symptoms and inappropriately self-treat other medical conditions as food allergies. Thus, effective communication should focus on communicating with food-allergic consumers and other stakeholders and end-users, without increasing over-reporting of food intolerance within the non-allergic population.

\section{Emerging allergy-communication issues}

There is potential for novel proteins from conventional or genetically modified sources to produce an allergic response in vulnerable individuals, as crops produced with agricultural biotechnology ultimately result in the introduction of novel proteins in specific foods (Oehlschlager et al. 2001; Taylor and Hefle 2001). The communication issue here relates to the provision of information about the efficacy of safety testing rather than health communication per se.

With respect to allergenicity and novel foods, it is also important to consider reactions of key stakeholders through the entire food chain, from producers through to retailers, as many mitigation strategies may have economic or resource implications. For example, opposition to the introduction of genetically modified crops may be perceived to compromise the secondary use of agricultural land as a leisure resource by the general population, which may then have a secondary impact on the use of agricultural resources within the farming community. Food manufacturers as well as non-allergic consumers may oppose the introduction of extra costs into the manufacturing process through the need for segregation of potentially allergenic ingredients within production plants, particularly if such segregation becomes a statutory requirement.

It is, of course, possible that allergic consumers may be more likely to accept innovations to reduce potential allergenicity in novel foods compared to non-allergic consumers. Allergic consumers may be more likely than non-allergic consumers to perceive increased risk associated with the introduction of novel allergens. Nonallergic consumers may be more likely to make decisions about the acceptability of different novel foods based on their beliefs about production techniques, motives of producers regarding the introduction of foods produced using such processes into the supply chain, and so forth. It is also possible that the communication needs of these two groups are different, as allergic consumers may need more information about potential specific health impacts, whereas non-allergic consumers may prefer more information about the wider impacts of technology on society. Effective labelling is contingent on efficient product and ingredient management through the food chain.

Other issues specifically refer to the development and implementation of emerging technologies in food production, and to matters associated with societal acceptance of these technologies. Communication must, of course, take due account of existing and emerging regulatory frameworks that also deal with allergy. The current regulatory framework focuses on the labelling of ingredients in pre-packed foods, and embraces a mechanism for establishing the allergenic potential of different allergens. Current globalization of the food chain is resulting in increased imports of new exotic food products (e.g. fresh fruits and vegetables) into the European market. The increased supply of such novel foods has resulted in the introduction of new potential allergens 
into the diet. One prominent example is the kiwi fruit (Actinidia chinensis), to which a relatively large number of Europeans and Americans are allergic (Rudeschko et al. 1998).

Rapid developments in plant breeding and molecular biology (including genetic modification) and progress in food-processing technologies results in other sources of novel foods being introduced into the market. For example, the introduction of new technologies into food production may result in the introduction of novel (potentially allergenic) proteins into food chains and products where consumers would not expect them to be. For example, Starlink maize has been produced using genetic modification. It contains an insecticidal protein from Bacillus thuringiensis (Bt) that protects maize plants from insect damage. Thus it is important to investigate the potential allergenicity of the $B t$ toxin for humans, using transparent assessment systems open to public and end-user scrutiny. In the case of Starlink, no potentially allergenic proteins have been identified. In contrast, an albumin gene was introduced into soy to improve its protein quality. The recombinant protein proved to be a major Brazil-nut allergen, and further development was stopped (Gilissen and Nap 1997; Gilissen 1998). Advances in processing techniques may keep labile allergens intact, or, conversely, enable specific destruction of allergen activity (Davis, Smales and James 2001; Soler-Rivas and Wichers 2001).

\section{Labelling as a communication method}

One form of communication that may be extremely useful to allergic consumers is that of product labelling. As well as the effects of allergic illness itself, allergic individuals must learn to cope with constantly exercising extreme vigilance when examining products for potentially problematic ingredients. Coping mechanisms must also be responsive to individuals' anxiety about their allergic condition (particularly in cases of extreme responses such as anaphylactic shock), concerns about crosscontamination, and potentially restricted social activity. This may become more of a problem as the number of foods to which a particular child or adult is allergic increases (Sicherer, Noone and Muñoz-Furlong 2001).

The only treatment for food allergy is, at the present time, avoidance of target foods by sensitive individuals (Ortolani et al. 1999). Joshi et al. (2002) report that the ability of parents of food-allergic children to read food labels accurately is very poor, primarily because of the complexity and ambiguity of information provided. This could result in accidental ingestion of hidden allergens, which has the potential to be fatal. Furthermore, in some cases poor labelling practices and so-called precautionary labelling might also lead to unnecessary restrictions in the child's diet (e.g. Hourihane 2001b; McCabe et al. 2001).

There is a requirement under the Novel Foods Regulation to assess allergenicity, but there is no requirement to assess the allergenicity of existing foods more generally. The current regulatory framework does not address the labelling, presentation and advertising of ingredients in foods that are not pre-packaged (e.g. local/in-store bakery, delicatessen, market stalls, salad bars and so forth) or in the catering sector. Neither does the regulation currently consider the necessary standardization, certification and accreditation measures and systems. It is suggested here that communication and legislation be harmonized to optimize their effects on public health. 
Food-induced anaphylaxis in allergic individuals already aware of their allergy happens most at 'safe sites', such as homes, school, workplaces and hospitals (Eigenmann and Zamora 2002) (although see Yunginger et al. 1988).

One conclusion that can be drawn is that an important strategy to avoid accidental reactions includes clear labelling of forbidden foods, and increased information provision at all levels. Effective communication includes providing information interventions that maximize consumer understanding and interpretation of food-label information, as well as dealing with worry about improperly or incompletely labelled products (Wood 2002).

An additional labelling problem relates to changes in ingredients in processed foods, and how this is communicated to potentially vulnerable consumers. Thus, labelling communication must also address changes in ingredients in some manufactured foods. Despite the potentially positive impact on quality of life for allergic consumers, there has been little empirical investigation into, for example, optimal labelling practices for potentially allergenic ingredients. Cross-cultural differences are also likely to exist in local preferences for labelling. The potential differences in the severity with which different allergic individuals may react to different amounts of an allergenic food may also influence their labelling preferences.

\section{Message framing in communication}

The role of message framing (i.e. presenting information in terms of either health benefit or health risk) in communicating information about food allergies may be a useful framework to follow. It has been shown that framing health messages in terms of either gains or losses can influence the health behaviours that people adopt (Rothman and Salovey 1997). More specifically, gain-framed messages (which emphasize the benefits of performing a behaviour) have been found to be more effective in encouraging people to adopt preventive behaviours. In contrast lossframed messages (which emphasize the costs of not performing a behaviour) have been shown to be more effective when persuading people to adopt screening or illness-detection behaviours (e.g. Rothman et al. 1999).

This paradigm may be of use when developing communication strategies for allergic individuals or, in the case of allergic children, their parents (Knibb et al. 1999b). Gain-framed messaging may be more effective in communicating information aimed at avoidance of allergens to prevent a reaction, particularly in the adolescent group who are most at risk of accidental reactions due to lack of realistic risk assessment. Previous methods may have focused on the consequences of a reaction, whereas more effective methods may be to emphasize the benefits to quality of life and health in maintaining vigilance and carrying an EpiPen ${ }^{\circledR}$ at all times. Loss-framed messaging may be more affective in communicating information regarding screening for allergic reactions, particularly in the self-diagnosed perceived food-intolerant group, or in parents who have diagnosed food allergy or intolerance in their child themselves. The risks of nutritional inadequacy of unnecessarily restricted diets or food avoidance could also be promoted.

\section{Information needs of specific stakeholders}

\section{Food retailers}

Of course, information needs may vary between different stakeholders. For example, food retailers have to deal with the potential impact of food allergens on 
consumers. In order to optimize communication with consumers about allergy issues, retailers need to have appropriately trained staff. Training, of course, requires the identification of reputable and trustworthy sources of information about food allergies. At the same time the information has to be easy to understand, and restricted to the most important facts (e.g. frequently asked questions). Increasing retail staff's knowledge and competence regarding food-allergy matters should increase the confidence of allergic consumers regarding the purchase of food in supermarkets. Effective communication should transfer the information about food allergies from the staff to allergic consumers.

The most important barrier to the development of effective communication about food allergy is the financial situation of retailers and consumers. According to surveys (Pfaff personal communication), more consumers reported that their financial situation had weakened in the year 2002 than at any other time during the past 10 years. Consumer spending will depend on getting even larger discounts, and profits will depend on making even larger cost cuts. The financial situation and motives of both consumers and business favour continued disinflation. In a time of economic restraint, retailers constrict their training efforts. Very often they reduce the number of staff and increase the self-serving product range. A second barrier to the development of effective communication is the legislative situation currently in force. Due to the reversal of the burden of proof retailers are responsible for all the information the staff gives to consumers. That means compensation for pain and suffering could be possible if retailers provide the wrong information. Under these circumstances, it is possible that retailers may dispense with providing any information about food allergy in order to avoid litigation.

Retailers have identified three stakeholder groups for communication in the field of food allergies: single adults with an own food allergy, couples (female or male adults with an information need for their partner), and families (in particular, adults such as parents with the need for information for their children). Single consumers are happy to explore different product options (as they take responsibility for their own exposure to risks), and want to try everything. They risk more due to their own responsibility. Couples and families are very reluctant to buy uncertain products, and are prepared to spend a lot of time to gain accurate information. Retailers need to tailor information to meet the needs of these different groups.

\section{Food manufacturers}

The food manufacturer is in a unique position as a stakeholder who needs to communicate directly with both suppliers and consumers. For the food manufacturer, there are basically two ways of protecting allergic consumers. The first is to tell them the allergen is present in the food, which is usually done by labelling. The second is to ensure, through appropriate manufacturing practices and controls, that the allergen is not present in the food. Clearly, neither appropriate labelling nor allergen control can be achieved without active communication with the supplier(s). Such communication needs to include clear understanding on the aims of the manufacturer's allergencontrol policies, as well as specific guidance on the allergens that are to be controlled, issues of cross-contact and the levels of allergen which are of concern. The manufacturer also needs to establish how well the supplier understands the allergen issue, and design strategies to address any shortcomings. Allergen labelling remains the principal means of informing allergic consumers, but it can be supplemented by other routes such as company help and information lines, product data sheets, and food-intolerance databases. The first requirement of an allergen label is that it should 
clearly convey the intended information, and there is a wealth of guidance on good practice in this field. Allergen labelling should, however, also avoid unnecessarily restricting allergic consumers' choice, while protecting them. It therefore needs to be based on risk or it will lack credibility and fail its purpose. Basing labelling on risk implies that there is a content of allergen ( $>0$ ) (usually termed threshold) below which there is no risk to the vast majority of food-allergy sufferers and the value of allergen labelling is outweighed by the disadvantages. Protecting individuals who may react severely to very small amounts may require different approaches, such as specialized food manufacturers. Minimizing the presence of allergen by cross-contact also raises the issue of what would be the highest acceptable level, bearing in mind that the more stringent the controls, the greater the resources that will need to be deployed to comply with them. Failure to achieve consistently the desired level of control also raises a host of risk-communication issues. These range from warning the consumer about the occasional presence of specific allergens (precautionary labelling), to informing them about product recalls.

\section{Risk regulators and public-health authorities}

In contrast, regulators need general information on the natural history of food allergy and intolerance to food additives, i.e. symptoms, severity, mechanisms, crossreactions, diagnosis and so forth. Thus, regulators need to understand more about the underlying causality and distribution of food allergy across populations in order to optimize consumer protection and communication. More specific information needs are related to understanding epidemiological data on the overall prevalence of food allergy, trends in epidemiology, the prevalence of the most important food allergies, which foods cause food allergy across which populations, thresholds for allergy responses, the potential for hidden allergens (i.e. allergens in flavours, carrier substances and processing aids), measures to avoid cross-contamination with allergens in food production, the possibilities and limitations of methods to detect allergens in food, and labelling rules.

\section{Health professionals}

For health professionals to be effective in their management of food allergy it is essential that they have an understanding of the mechanisms involved in IgE- and non-IgE-mediated food allergy to enable an appropriate diagnosis and treatment strategy to be reached (EAACI nomenclature task force proposes that an adverse reaction to food should be called food hypersensitivity. When immunologic mechanisms have been demonstrated, the appropriate term is food allergy; if the role of IgE is highlighted, the term is IgE-mediated food allergy, and when in an allergic reaction no IgE can be shown, the term is non-IgE-mediated food allergy. All other reactions should be referred to as nonallergic food hypersensitivity). This knowledge is pivotal in ensuring that appropriate information is passed onto the allergic consumer and creates a mental framework to help manage other relevant knowledge. Other information needs can be identified related to increasing knowledge about common manifestations of allergic reactions to foods. As well as those symptoms commonly associated with allergic reactions to food, such as anaphylaxis, rash, itching and hives, the possibility that other symptoms (such as diarrhoea and vomiting, constipation and headaches) are related to food allergy also needs to be considered.

Health professionals need to know which foods are commonly associated with food-allergic reactions, as well as understanding which foods can induce allergic 
symptoms. This must also include those foods associated with non-IgE-mediated reactions to foods as well as those associated with immediate reactions. Health professionals also need information about diagnosis of food allergy, which can be complex, particularly for non-IgE-mediated conditions. For example, one method is often inadequate in diagnosing a food allergy, and a combination of methods including serological IgE and T-cell measurements, dietary exclusion and an accurate clinical history are needed to achieve an accurate diagnosis.

Treatment strategies for the management of the food-allergic consumer will differ according to the speciality of the health professional. For example, physicians need to be aware of asthma and eczema treatment medication as well as how environmental factors may affect the allergic manifestation. Dieticians need to know how to eliminate a particular food or group of foods from the allergic consumer's diet, and with what to replace these foods to ensure the diet is still nutritionally complete. Physiotherapists need to be aware of the association between exercise and allergicreaction severity and how to manage this.

Finally, there is a wealth of information available to the food-allergic consumer, but often consumers do not know how to access this information. For example 'free from a particular ingredient' lists from supermarkets, or contact details of support groups are not always immediately accessible or available to consumers. It is also important to be aware of what inaccurate or erroneous information the allergic consumer might receive, and from which sources, in order to provide the best advice possible for consumers. This will ensure the food-allergic consumers have a full and accurate understanding of the relevant issues, which will empower them to feel capable of managing their allergic condition.

\section{Food-allergic individuals}

Food-allergic individuals, and the public at large, must understand that all foods can induce allergic symptoms, which can appear in different target organs: in the skin, in oral cavity, in the nose and eyes, lungs and gastrointestinal tract, cardiovascular system, even in the nervous system, and in the worst case an anaphylactic reaction may occur. The severity of reactions varies between different individuals, and for the same individuals at different times, from mild to even life-threatening. Unfortunately the factors that determine this variability between and within individuals have not been established conclusively.

Although it is now accepted that No Observed Adverse Effect Levels (NOAEL) exist for allergens (Taylor and Hefle 2001), their value has not been determined in many cases. Sensitization may happen by different routes: oral-mucosal, by skin and also by inhalation. That is, ingestion of the food is not always necessary either to develop a food allergy or to react to a food allergen. Diagnostic methods are skinprick testing, measurement of specific IgE antibodies from sera and eliminationprovocation diets, of which none are $100 \%$ sensitive and specific. The 'gold standard' is the double-blind placebo-controlled food challenge (DBPCFC), which can only be conducted in specialized clinics. Individuals with multiple food allergies, especially children and those with extremely restricted diets, must be under medical care: doctor, allergy nurse and allergy dietician. In the optimal case the allergic consumer always visits the same doctor. From a communication point of view, it is extremely important that the allergic person informs his or her doctor that he/she uses alternative remedies, as these may interfere with other treatments or even induce allergic symptoms in some cases. All consumers with health-related food-avoidance needs share some communication needs, whether they have food intolerance, food allergy, coeliac 
disease or a variety of other conditions. However, for those whose symptoms may become life-threatening, effective allergen avoidance and appropriate emergency rescue treatment are essential. Furthermore, communication requirements can be identified at different stages of life, which entails the development of different communication approaches.

Parents wishing to prevent their baby becoming allergic need to know whether any foods consumed by the mother or the baby, or other route of exposure to allergens (for example, through contact) may sensitize their baby, setting up the risk of allergic reactions in the future. Parents also need to know whether their baby and any siblings are more likely than others to be atopic, i.e. to produce IgE antibodies against environmental allergens and different foods. Information is required relating to how the different types of allergic symptoms (for example, eczema, asthma, food allergy, rhinitis) are linked and how to alleviate symptoms, as well as consistent evidencebased feeding and weaning advice and support from midwives and post-birth health professionals who understand allergic disease.

Families with atopic children need good primary medical care from GPs who need to be well supported by convenient and accessible specialist allergy clinical support. A proper diagnosis always involves taking a full medical history as well as possible skin-prick, blood and challenge tests. Allergic individuals need a clear understanding of what they must avoid, what the possible symptoms may be and how to recognize them. They need training in addition to the information they have received from their GP or allergy specialist, often from a specialist allergy dietician in allergen avoidance (whilst maintaining a balanced diet) and also from a specialist nurse or support staff member in managing emergencies and administering emergency medication. It is important for specialist patient care to be accessible because as children develop their condition may well change.

The handover of care of allergic children to carers, nursery staff, schools and other situations where somebody else is responsible for the necessary vigilance and possible emergency response requires both formal and informal communication. Both health and safety, and food-safety protocols need to be in place to control allergens and to prevent inadvertent exposure of the person at risk. Special measures will need to be in place to protect those at risk when food and drink are consumed or used in learning. Within educational situations, allergy needs to be integrated into the formal curriculum (for example, in food technology, science, personal, social and health education) as well as addressed within the ethos of the organization. University and college students are at particular risk, so food-allergy risks need to be addressed across campuses and in places where they eat.

People with food allergies and other health-related food avoidance need to know that the food they buy and eat is exactly what they think it is (implying the need for implementation of standards) and that it has been protected from any contamination which may harm them. Any labelling of ingredients or additional information about allergen contamination on a packet, on a menu, on a website, from a member of staff or from any other route may communicate a potentially life-threatening risk, and must be communicated in an effective way. The communication needs in food standards and food safety are many and varied, but must include the effective transfer of information about any risk that has proved impossible to control through the entire length of the food supply chain. This will enable the allergic end-consumer to decide whether or not to eat a particular food. In practice, this will also include transmitting emergency risk information effectively (for example, recall notices and product alerts to those at greatest risk). 
People eating out need to take particular precautions and also know how to manage an emergency and report a suspected allergic reaction to the appropriate enforcement authority. Food alerts, food recalls and other practical precautions need to be available and effective. Data from enforcement activities, such as audits and sampling, need to be collated and studied so that risks can be identified and precautions put in place.

There are some specific communications issues that need to be addressed. For example, if allergic people are wearing medical identification to indicate their condition, other people in a range of situations must understand this. Information about administering, using or maintaining emergency medication, emergency first aid, the role of pharmacists in supporting allergic individuals in an emergency must be made accessible more generally, as should the provision of general allergy information. The role of paramedics and ambulance crews, as well as practical measures to bring emergency help to people at risk, need to be included. It is also important for allergic consumers to be able to access up to date and credible information about scientific and medical developments (for example, improvements in techniques for diagnosis, preventer vaccines and other innovations that may reduce their risk or improve their ability to manage it).

Allergic people who are travelling have special communication needs: These include pre-planning long-distance travel, carrying 'safe' food, alerting airlines and other travel companies, carrying adequate stocks of preventer and rescue medication, and communicating the allergy risk to appropriate authorities en route. They also need to communicate their allergy and if necessary call for emergency help in other languages.

Finally, if an allergic person has suffered a reaction, it is important that it is thoroughly investigated and attributed if possible. Any failure of a critical control (for example, labelling or dialogue with a staff member in a responsible organization) needs to be examined and measures put in place to prevent recurrence. Suspected allergy (or food-allergen-triggered asthma) deaths need to be investigated, appropriate samples taken for analysis and information about the circumstances surrounding the death (including any dialogue, labelling or written information) examined. It is important that such data are collected consistently and made available nationally, across the EU and indeed world-wide so that any preventative measures can be taken and also so that the impact of allergy is properly understood.

Protection of the food-allergic consumer is a shared responsibility between food manufacturer and consumer, as well as other stakeholders. These stakeholders have a key role in attaining consensus as to the goals of allergen risk management. One conclusion may be that some consumers may be so sensitive that it is not possible to protect them against reactions and produce food at an acceptable cost to the vast majority and they would need to be advised accordingly.

\section{Stakeholder priorities for food-allergy communication needs}

\section{Aim and method}

The aim of the stakeholder analysis was to develop a list of important food-allergy communication needs, and to identify the specific needs of different stakeholder groups. Although these have been outlined above, it is important to determine whether the needs of different stakeholders are sufficiently different to warrant development of targeted information strategies. The Communication Issues List (Table 1) was developed to meet this aim. The list was designed to identify the types of information about food allergy that different stakeholder groups would benefit from having 
available. The list was developed from examination of the food-allergy literature for potential communication issues, and information provided by discussion with different stakeholders (patient groups, health professionals, manufacturing industry, retailers, regulators and social scientists specializing in risk-communication issues) at the inaugural InformAll meeting in Norwich, UK (February 2003).

Respondents were asked to read the list in the first column, and then identify which of the stakeholder groups they thought would benefit from having information available about each item on the list. They were told that they could tick as many stakeholder groups as they wanted for each item on the list. Respondents were specifically asked to provide details of any stakeholder groups or communication issues that they felt were missing from the list. They were also given an opportunity to provide any other comments at the end of the form. Respondents were asked to state of which stakeholder group they judged themselves to be representative. Respondents came from both the InformAll consortium, as well as additional stakeholders in the food-allergy and food-industry area.

\section{Results}

The results are summarized in Table 1 . Table 2 lists the stakeholder groups judged to need information about food allergy, this includes the original stakeholder groups listed in the Communication Issues list, and the additional groups identified as part of the consultation exercise. Table 3 identifies additional communication issues that resulted from the consultation exercise. In total, forty-two responses were received from various stakeholders. Representatives from a number of the key stakeholder groups responded including:

- 18 from the food industry (6 food manufacturers, 2 food retailers, 4 caterers, 6 general food industry)

- 14 from research institutes and universities

- 5 patient groups' representatives or food-allergic consumers

- 4 health professionals

- 4 from other groups (trading standards, science communication, allergen test-kit manufacturers, and regulators).

Generally, there was consensus that different stakeholders were interested in receiving all available information, although some stakeholders identified specific priorities. The results indicated that virtually all of the communication issues were judged to be important for patient groups and food-allergic consumers, as well as health professionals. Information about what causes food allergy was judged to be important for all stakeholder groups. Other general information such as what types of symptoms food allergy causes, what people can do to avoid becoming allergic, what can be done to ease symptoms were judged to be particularly relevant for the general public, allergic consumers and patient groups, health professionals and educationalists.

The most useful information for regulators was judged to be information about what causes food allergy, how much allergenic material is required for a reaction, how many people are allergic to different foods, and how severe symptoms are (particularly in relation to dose). Regulators would also be interested in understanding why and when precautionary labelling is appropriate, and how and under what circumstances cross-contact occurs. Systems and procedures judged to be important for regulators included the development of a grading system for precautionary 


\begin{tabular}{|c|c|c|c|c|c|c|c|c|c|c|c|c|c|c|c|c|c|}
\hline (אf!ว & t & N & e & a & - & - & -1 & $\neg$ & -1 & N & N & N & n & m & 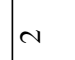 & N & v \\
\hline р!рәи әчцL & |י্লি & $\bar{\imath}$ & $\vec{m}$ & i & $\stackrel{2}{2}$ & $\vec{m}$ & ని & $\stackrel{2}{N}$ & $\stackrel{\infty}{\sim}$ & $\approx$ & สิ & $\stackrel{\infty}{-}$ & $\tilde{N}$ & A & $\hat{\curvearrowright}$ & $\approx$ & กิ \\
\hline$i^{2} \boldsymbol{W}$ & $\tilde{m}$ & m & 2ิ & ) & 2 & $\widehat{\curvearrowright}$ & $\stackrel{2}{\sim}$ & ৯ & ৯ & ন & $\stackrel{\sim}{\sim}$ & ล & $\ddot{N}$ & $\ddot{N}$ & $\infty$ & $\stackrel{\sim}{2}$ & $\approx$ \\
\hline 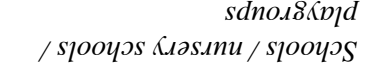 & $m_{m}^{\infty}$ & $\stackrel{\mathscr{N}}{\sim}$ & $\approx$ & $\stackrel{\infty}{\sim}$ & m & 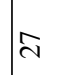 & $\stackrel{\infty}{\sim}$ & $\exists$ & m & 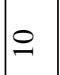 & $\infty$ & $\stackrel{ }{\circ}$ & $\Rightarrow$ & $\stackrel{\sim}{-}$ & $\approx$ & $\stackrel{\sim}{\rightarrow}$ & a \\
\hline ग!lqnd рицаиә & $\vec{m}$ & 9 & ㅇ & $\approx$ & $\stackrel{\infty}{\sim}$ & $\ddot{m}$ & $\stackrel{\sim}{\sim}$ & $g$ & $\stackrel{\sim}{\sim}$ & กิ & $\approx$ & $\approx$ & ลี & $\stackrel{L}{N}$ & $\stackrel{\sim}{N}$ & $\bar{\lambda}$ & $\mathscr{0}$ \\
\hline s.ว.นวџрว & 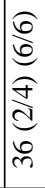 & 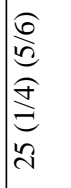 & 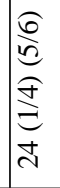 & 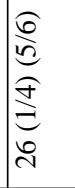 & 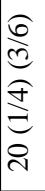 & 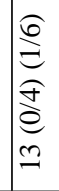 & 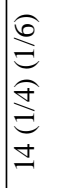 & 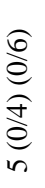 & 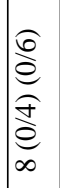 & 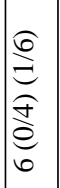 & 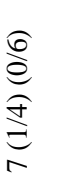 & 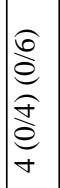 & 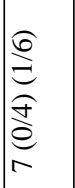 & 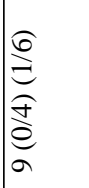 & 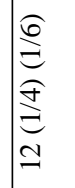 & 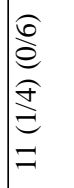 & 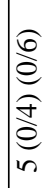 \\
\hline 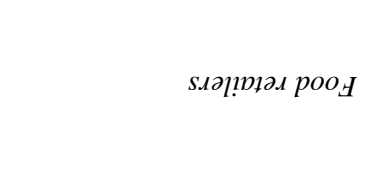 & 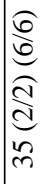 & 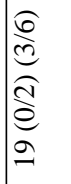 & 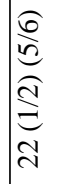 & 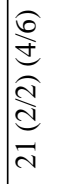 & 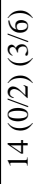 & 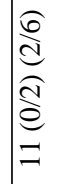 & 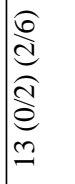 & 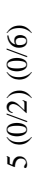 & 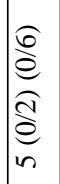 & 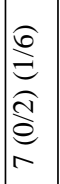 & 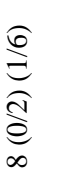 & 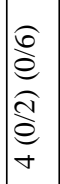 & 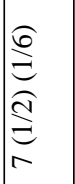 & 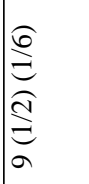 & 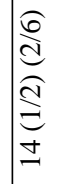 & 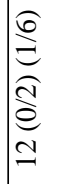 & 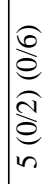 \\
\hline 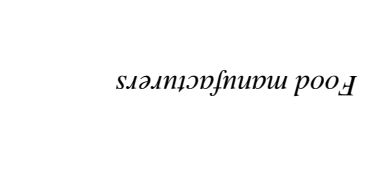 & $\begin{array}{l}0 \\
0 \\
0 \\
0 \\
0 \\
0 \\
0 \\
0 \\
0 \\
m\end{array}$ & 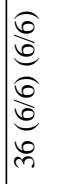 & 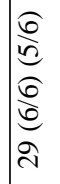 & 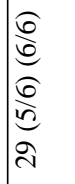 & $\begin{array}{l}0 \\
0 \\
0 \\
0 \\
0 \\
0 \\
0 \\
0 \\
-1\end{array}$ & 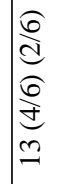 & 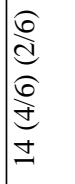 & 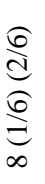 & 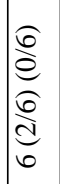 & 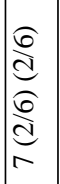 & 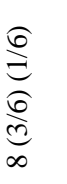 & 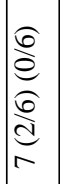 & 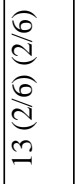 & 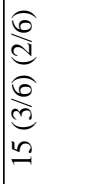 & $\begin{array}{l}0 \\
0 \\
d \\
0 \\
0 \\
0 \\
0 \\
9\end{array}$ & 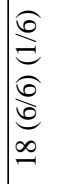 & 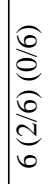 \\
\hline 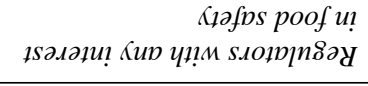 & m & $\ddot{m}$ & $\ddot{m}$ & হి & $\stackrel{\infty}{\rightarrow}$ & $\approx$ & $\stackrel{2}{-1}$ & $\wedge$ & เ & $\exists$ & $\exists$ & $\infty$ & 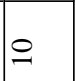 & $\approx$ & กิ & $\stackrel{\infty}{\sim}$ & $\Lambda$ \\
\hline 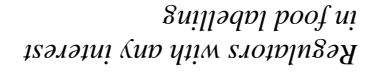 & 边 & ले & $\vec{m}$ & ì & $\stackrel{\oplus}{-}$ & $a$ & $\exists$ & $\nabla$ & A & a & $\exists$ & $\infty$ & $\infty$ & 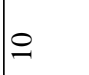 & $\approx$ & $\stackrel{\oplus}{-}$ & t \\
\hline 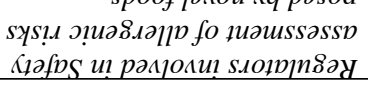 & $\hat{m}$ & $\hat{m}$ & $\ddot{m}$ & ले & $\approx$ & $\approx$ & 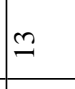 & 은 & L & $\exists$ & $\approx$ & 운 & $\exists$ & 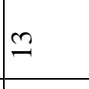 & กิ & $\overline{\text { }}$ & in \\
\hline 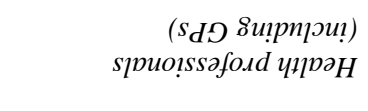 & 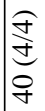 & 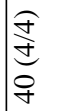 & 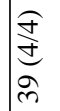 & 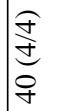 & 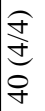 & 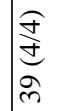 & 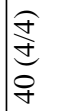 & 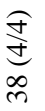 & $\begin{array}{l}\underset{f}{\nexists} \\
\stackrel{f}{\&}\end{array}$ & 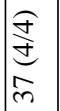 & 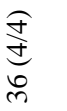 & 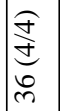 & 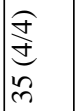 & 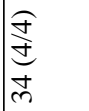 & 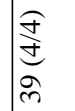 & 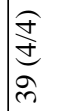 & 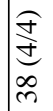 \\
\hline 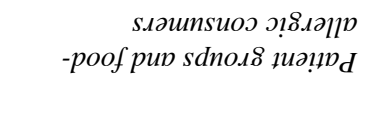 & 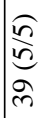 & 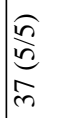 & 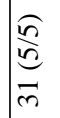 & 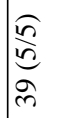 & $\frac{12}{10}$ & 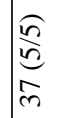 & $\begin{array}{l}\frac{1}{2} \\
\frac{\omega}{0} \\
\stackrel{q}{q}\end{array}$ & 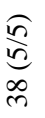 & 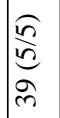 & 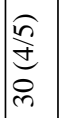 & 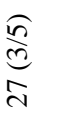 & 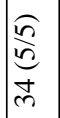 & $\begin{array}{l}\frac{\hat{D}}{2} \\
\text { ف्र } \\
\hat{\mathrm{m}}\end{array}$ & 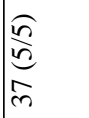 & 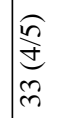 & 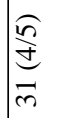 & 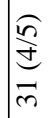 \\
\hline 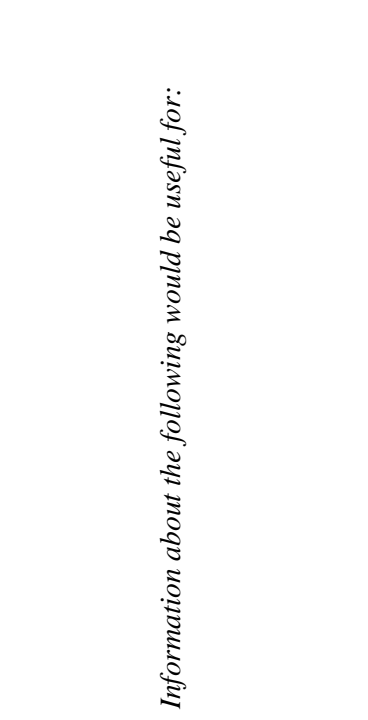 & 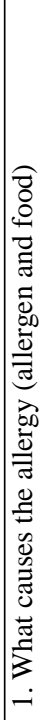 & 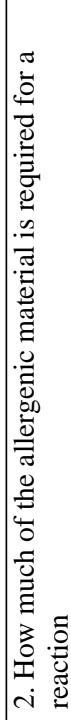 & 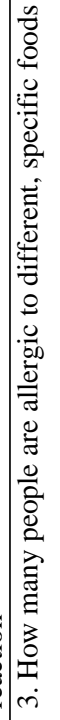 & 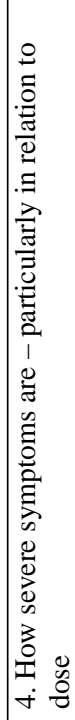 & 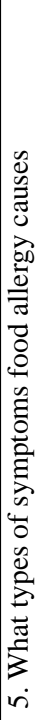 & 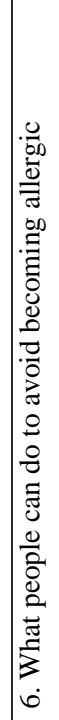 & 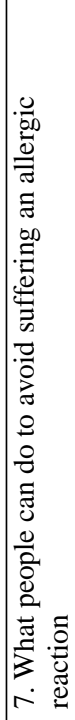 & 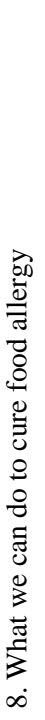 & 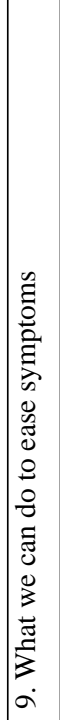 & 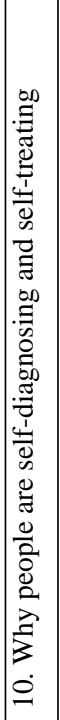 & 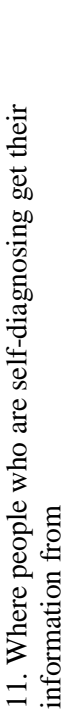 & 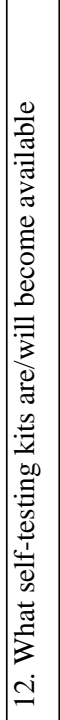 & 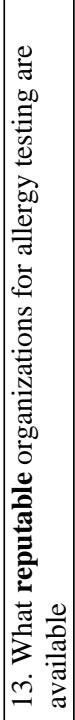 & 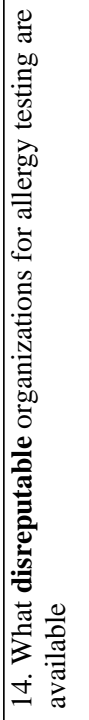 & 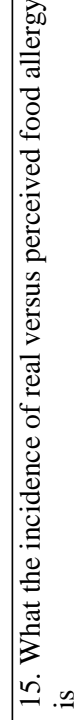 & 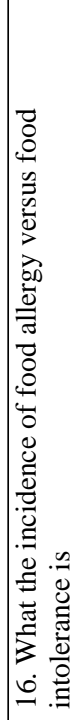 & 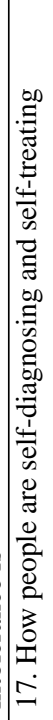 \\
\hline
\end{tabular}




\begin{tabular}{|c|c|c|c|c|c|c|c|c|c|c|c|c|c|c|c|c|c|c|c|c|}
\hline- & - & N & N & N & $\neg$ & $\neg$ & $\neg$ & $\neg$ & - & - & -1 & $\neg$ & - & - & $\neg$ & - & -1 & - & - & N \\
\hline స & $\stackrel{\sim}{ }$ & $\approx$ & $\stackrel{\sim}{ }$ & $\approx$ & $\stackrel{\infty}{-1}$ & $\infty$ & $\infty$ & $\infty$ & ـ & L & $\sigma$ & $\vec{N}$ & $\infty$ & $\exists$ & 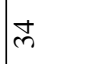 & $\stackrel{m}{\rightarrow}$ & صا & $m$ & 0 & ما \\
\hline I & $\stackrel{\sim}{ }$ & $\stackrel{\infty}{\sim}$ & $\stackrel{\infty}{\sim}$ & $\hat{\lambda}$ & $\vec{N}$ & 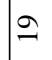 & 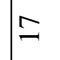 & $\stackrel{0}{-1}$ & $\nexists$ & $\leadsto$ & $\stackrel{2}{2}$ & 9 & 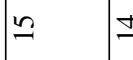 & 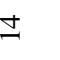 & $\approx$ & $\vec{N}$ & $\approx$ & o & 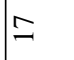 & 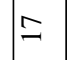 \\
\hline$\stackrel{0}{1}$ & $\stackrel{-1}{-1}$ & $\tilde{m}$ & $\vec{m}$ & Dి & mे & $\vec{\sim}$ & $\mathscr{m}$ & $\approx$ & $\approx$ & $\exists$ & $\stackrel{\infty}{\sim}$ & $\vec{N}$ & 웅 & $\ddot{\sim}$ & $\sigma$ & $\approx$ & $\stackrel{\sim}{\longrightarrow}$ & L & $\stackrel{\infty}{-1}$ & $\stackrel{\sim}{\longrightarrow}$ \\
\hline 9 & ส & 用 & 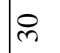 & $\mathscr{N}$ & $\approx$ & $\stackrel{-}{-1}$ & \pm & $\stackrel{\infty}{-\infty}$ & $\stackrel{2}{2}$ & $\stackrel{1}{2}$ & $\tilde{\sim}$ & $\infty$ & \pm & $\stackrel{\Delta}{d}$ & 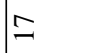 & 9 & $\approx$ & $\vec{N}$ & $\Rightarrow$ & กิ \\
\hline 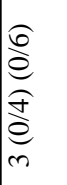 & 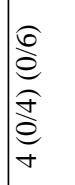 & 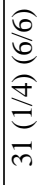 & 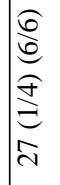 & 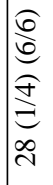 & 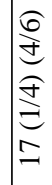 & 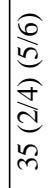 & 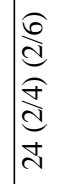 & 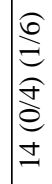 & 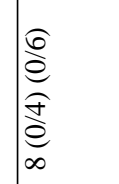 & 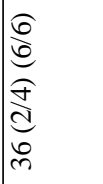 & 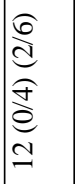 & 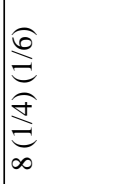 & 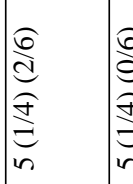 & 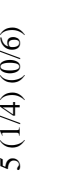 & 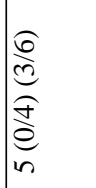 & 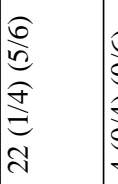 & 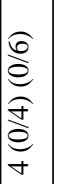 & 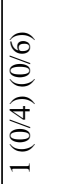 & 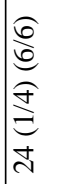 & 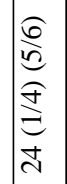 \\
\hline 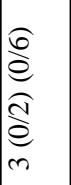 & 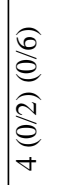 & 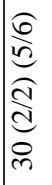 & 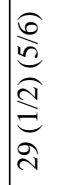 & 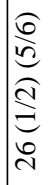 & 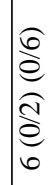 & 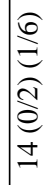 & 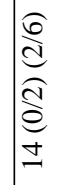 & 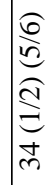 & 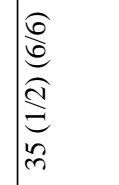 & 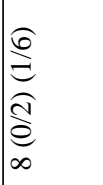 & 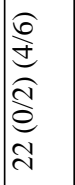 & 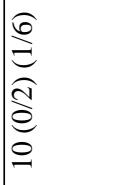 & 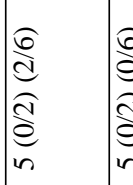 & 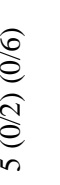 & 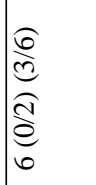 & 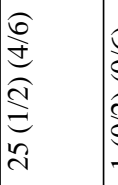 & 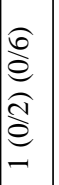 & 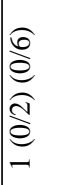 & 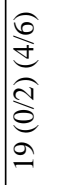 & 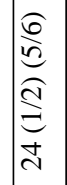 \\
\hline 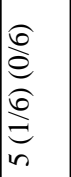 & 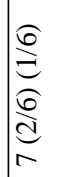 & 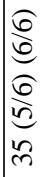 & $\begin{array}{l}0 \\
0 \\
\omega \\
0 \\
0 \\
\omega 0 \\
\tilde{\omega} \\
m\end{array}$ & 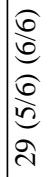 & 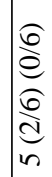 & 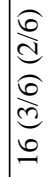 & 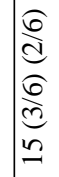 & & 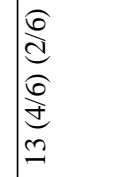 & 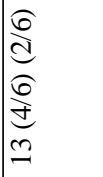 & 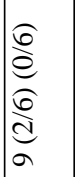 & 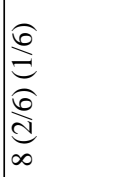 & 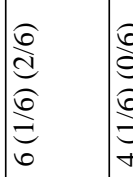 & 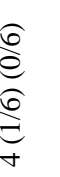 & 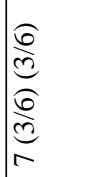 & 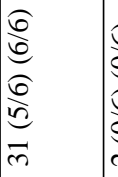 & 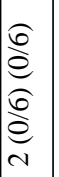 & 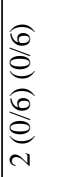 & 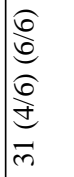 & $\begin{array}{l}0 \\
0 \\
0 \\
0 \\
0 \\
0 \\
\bar{m}\end{array}$ \\
\hline$\wedge$ & 으 & $\tilde{m}$ & 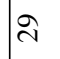 & $\ddot{\sim}$ & $m$ & $\stackrel{9}{2}$ & $\stackrel{0}{-1}$ & $\exists$ & $\infty$ & $\infty$ & 0 & N & ब & $\nabla$ & ब & I & N & Ln & $\approx$ & $\stackrel{\mathscr{N}}{ }$ \\
\hline$\nabla$ & م & $\hat{m}$ & $\stackrel{m}{m}$ & $\stackrel{\llcorner}{\sim}$ & v & $\stackrel{0}{-1}$ & $\stackrel{2}{\longrightarrow}$ & $\stackrel{2}{\longrightarrow}$ & 0 & 0 & ナ & $m$ & $m$ & $m$ & N & m & $\neg$ & $m$ & 2 & $\mathscr{N}$ \\
\hline$\nabla$ & n & $\bar{m}$ & 周 & $\approx$ & $m$ & $\exists$ & $\sigma$ & $a$ & مـ & מ & L & N & | & $\nabla$ & m & ป & - & $\theta$ & 녹 & $\mathscr{\varphi}$ \\
\hline 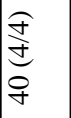 & 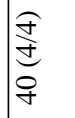 & 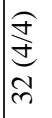 & 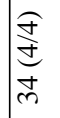 & 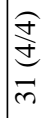 & $\mid \begin{array}{l}\stackrel{f}{\mathcal{J}} \\
\stackrel{f}{\&}\end{array}$ & $\underset{\substack{d \\
\text { d }}}{\stackrel{f}{d}}$ & & 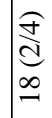 & 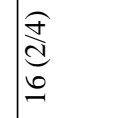 & 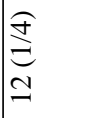 & $\underset{\vec{N}}{\stackrel{f}{\Xi}}$ & $\begin{array}{l}\underset{f}{d} \\
\underset{d}{d}\end{array}$ & 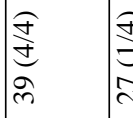 & 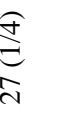 & 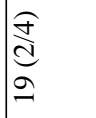 & 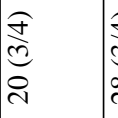 & 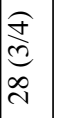 & 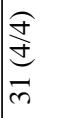 & $\underset{\exists}{\stackrel{f}{d}}$ & 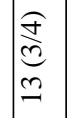 \\
\hline 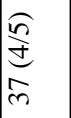 & 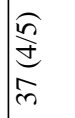 & 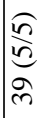 & 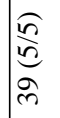 & 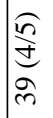 & 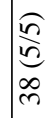 & 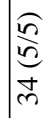 & $\begin{array}{l}\frac{0}{2} \\
\vec{n} \\
m \\
m\end{array}$ & 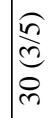 & 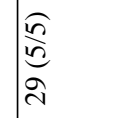 & 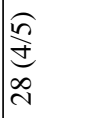 & $\begin{array}{l}\frac{1}{2} \\
\text { De } \\
\text { Ln } \\
m\end{array}$ & 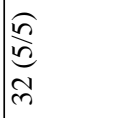 & 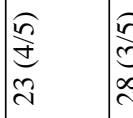 & 夜 & $\begin{array}{l}\frac{\mathfrak{D}}{\mathrm{d}} \\
\overline{\mathrm{N}}\end{array}$ & 昘 & 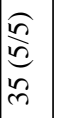 & 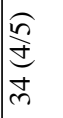 & 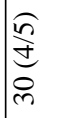 & $\begin{array}{l}\frac{1}{10} \\
\underset{m}{m} \\
m\end{array}$ \\
\hline 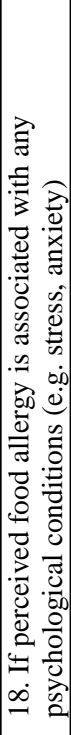 & 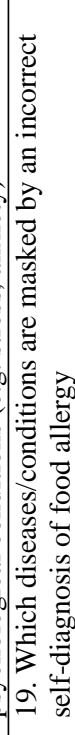 & 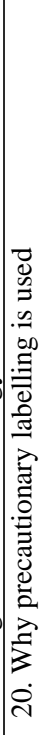 & 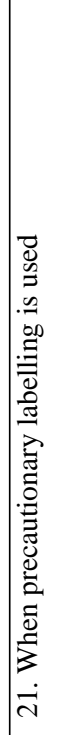 & 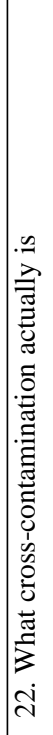 & 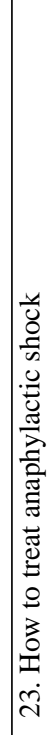 & 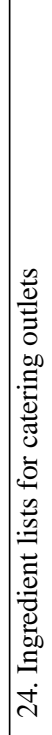 & 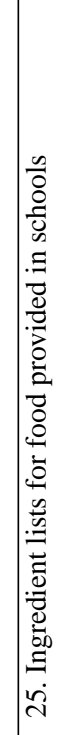 & 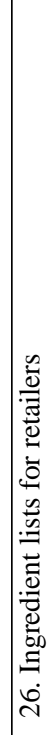 & 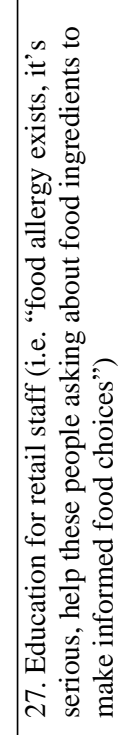 & 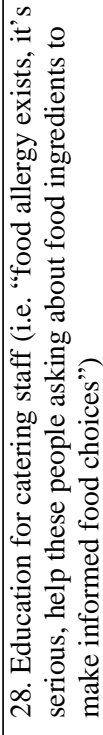 & 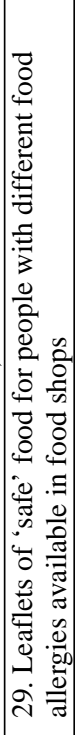 & 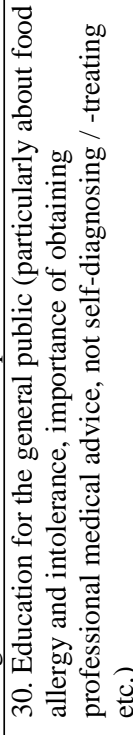 & 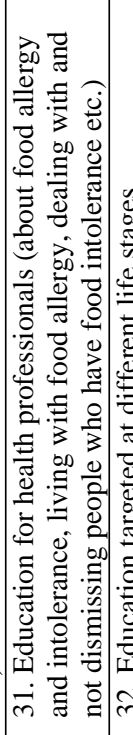 & 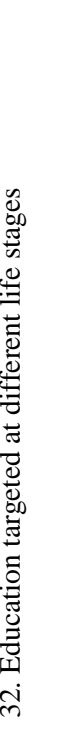 & 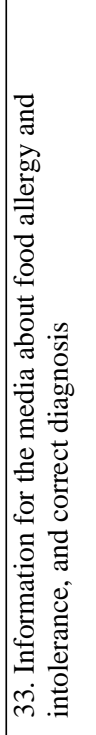 & 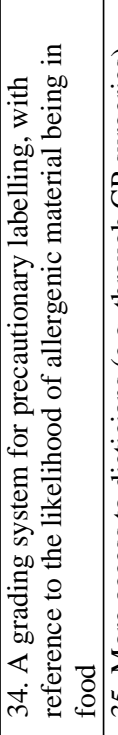 & 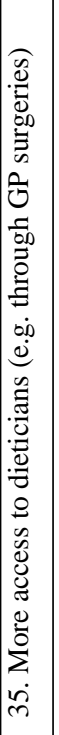 & 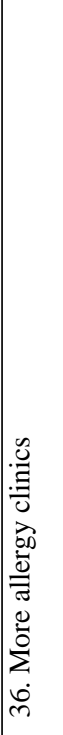 & 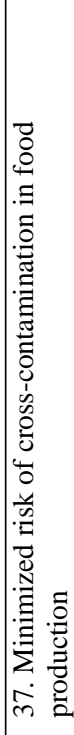 & 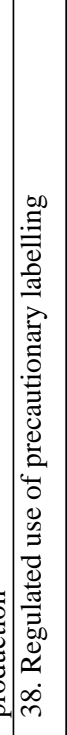 \\
\hline
\end{tabular}




\begin{tabular}{|c|c|c|c|c|c|c|c|c|c|}
\hline- & v & N & m & -1 & N & -1 & N & - & -1 \\
\hline$\nabla$ & $\sigma$ & n & م & $\nabla$ & $\exists$ & م & $\exists$ & $\wedge$ & $\exists$ \\
\hline 0 & $\stackrel{\infty}{\sim}$ & $\Rightarrow$ & $\exists$ & 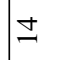 & $\bar{N}$ & $\exists$ & $\ddot{m}$ & $\approx$ & $\approx$ \\
\hline$\nabla$ & $\stackrel{\sim}{ }$ & $\exists$ & $\curvearrowright$ & $\infty$ & ก & $\stackrel{9}{-1}$ & $\ddot{\sim}$ & $\approx$ & $\bar{N}$ \\
\hline 0 & $\vec{\sim}$ & $\stackrel{\infty}{=}$ & $\infty$ & $\stackrel{\circ}{=}$ & $\overbrace{\sim}^{\infty}$ & 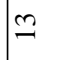 & $\stackrel{\sim}{N}$ & $\stackrel{\sim}{\sim}$ & $\stackrel{I}{\text { N }}$ \\
\hline 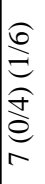 & 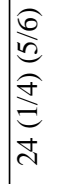 & 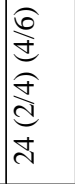 & 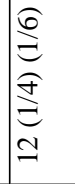 & 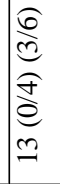 & 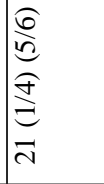 & 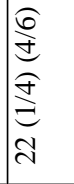 & 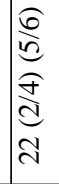 & 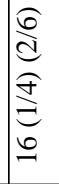 & 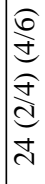 \\
\hline 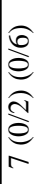 & 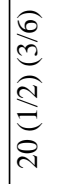 & 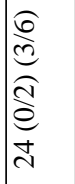 & 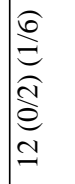 & 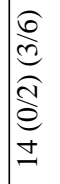 & 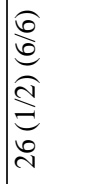 & 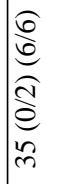 & 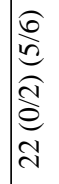 & 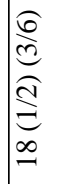 & 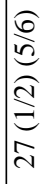 \\
\hline 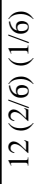 & 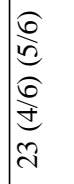 & $\begin{array}{l}0 \\
0 \\
0 \\
0 \\
0 \\
0 \\
\omega 0 \\
0 \\
0 \\
0\end{array}$ & 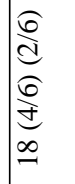 & 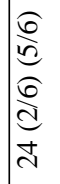 & 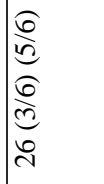 & 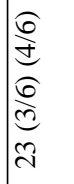 & 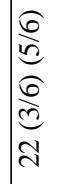 & 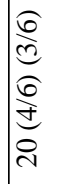 & 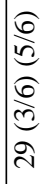 \\
\hline$\approx$ & $\approx$ & ని & $\stackrel{\infty}{\circledast}$ & 9 & $\approx$ & $\therefore$ & $\stackrel{2}{2}$ & $\approx$ & $\tilde{N}$ \\
\hline$\approx$ & $\ddot{\nu}$ & $\stackrel{\infty}{\infty}$ & $\approx$ & $\stackrel{\infty}{-}$ & $\hat{N}$ & $\stackrel{\infty}{-}$ & $\stackrel{0}{\circ}$ & $\stackrel{0}{-1}$ & Iิ \\
\hline$\circ$ & $\exists$ & İ & $\cong$ & $\Xi$ & $\stackrel{-1}{\infty}$ & $\exists$ & $\stackrel{\circ}{\circ}$ & $\ltimes$ & $\stackrel{\infty}{-}$ \\
\hline 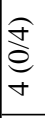 & 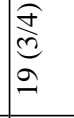 & 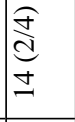 & $\underset{\substack{\stackrel{f}{d} \\
ِ \\
-1}}{ }$ & 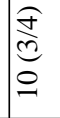 & $\begin{array}{l}\stackrel{f}{\stackrel{f}{d}} \\
\underset{N}{\sim}\end{array}$ & $\underset{\exists}{\stackrel{f}{d}}$ & 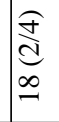 & 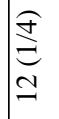 & 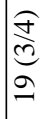 \\
\hline 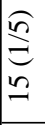 & 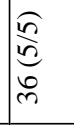 & 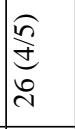 & 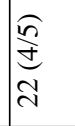 & 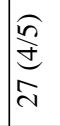 & 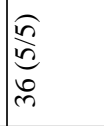 & 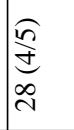 & 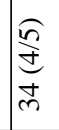 & 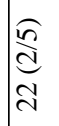 & 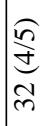 \\
\hline 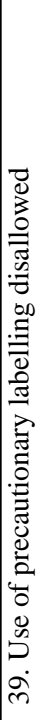 & 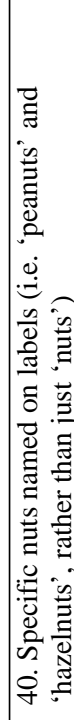 & 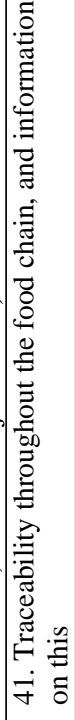 & 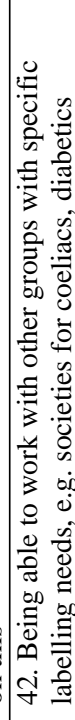 & 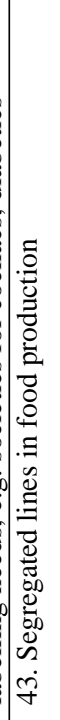 & 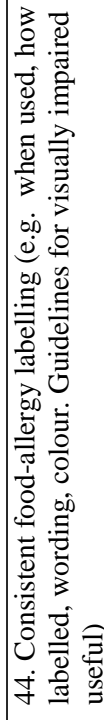 & 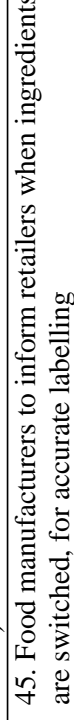 & 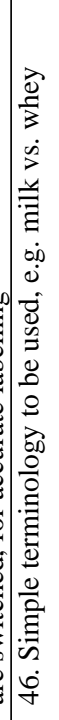 & 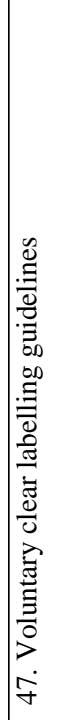 & 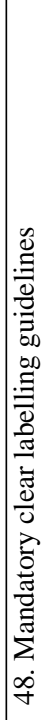 \\
\hline
\end{tabular}

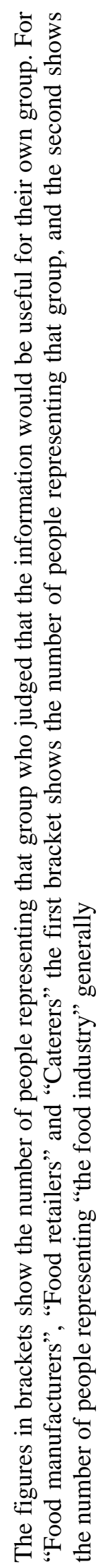


labelling. Regulators would also benefit from information about the statutory application of precautionary labelling, ingredient traceability throughout the food chain, consistent food-allergy labelling and mandatory clear labelling guidelines.

The same types of information and systems and procedures were judged to benefit food manufacturers. Food manufacturers were identified as potential beneficiaries from minimized risk of cross-contact, including rigorous application of segregated lines in food production. The responses for food retailers and caterers were very similar to each other. Information about what causes food allergy was judged to be very important for retailers and caterers. Information about why and when precautionary labelling is used, and information about cross-contamination, were also judged to be reasonably important for these groups. Information about how much allergenic material is required for a reaction, how many people are allergic to different specific foods, and the severity of symptoms were judged to be relatively less important for manufacturers. Although some large manufacturers considered these issues very important, they were not consulted as part of the stakeholder analysis. Ingredient lists for catering outlets and education for catering staff were important for caterers. Ingredient lists for retailers, education for retail staff and food manufacturers informing retailers when ingredients change in specific products, were important for food retailers. For both retailers and caterers, mandatory clear labelling guidelines were rated as extremely important. The provision of better information and education for specific groups (i.e. the general public, health professionals, catering staff and retail staff) were also rated highly, more so than for patient groups and food-allergic consumers.

The different stakeholder groups agreed that simple terminology, naming of specific nuts in products, consistent food-allergy labelling and regulated use of precautionary labelling were priorities. Mandatory clear labelling guidelines were preferred to voluntary guidelines. The sample was split over their opinion about whether patient groups and food-allergic consumers would benefit from having

Table 2. Key stakeholder groups identified before and during the stakeholder consultation exercise

- Food-allergic consumers and families and carers of food-allergic consumers (including child minders), patient groups representing food-allergic consumers

- Health professionals (including GPs and pharmacists)

- Regulators involved in safety assessment of allergenic risks posed by novel foods

- Regulators with any interest in food labelling

- Regulators with any interest in food safety (including Environmental Health Officers and Trading-Standards Officers)

- Food manufacturers (from small independent manufacturers who may be making specialist products to large manufacturers)

- Food retailers (from small independent shops to large retailers)

- Caterers (including street vendors, cafes and restaurants, school and staff canteens, 'meals-on-wheels', hospital kitchens etc)

- General public

- Consumer groups

- Schools / nursery schools / playgroups / universities (in pastoral role) / youth clubs / holiday clubs / girl/boy guides/scouts

- The media

- Food testing-kit manufacturers (for testing food and people)

- Interested academics 
Table 3. Additional communication issues identified as relevant in the stakeholder consultation exercise

- The difference between food allergy and intolerance (definitions), how they are related, and what causes the allergy

- Information about weaning (e.g. when to introduce solid foods, and when to introduce specific solid food)

- When to re-introduce foods to which allergic individuals are sensitive, and how to introduce them

- What is the procedure for consumer protection? (i.e. what are the consumers' rights if something goes wrong, and what action should they take e.g. if they have a reaction in a restaurant?)

- What legislation on labelling is there in different countries? (useful, for example, when people are travelling)

- Information about what foods are allergens (including a definition of what foods are 'nuts', and which processed and refined derivatives are allergens)

- Why you should see a qualified medical professional (e.g. your family doctor) for a proper diagnosis

- What might cross-react or exacerbate with diagnosed food allergy

- The relationship of food allergy with untreated asthma

- Information about the risks of cross-contamination associated with consuming loose foods and products made by individuals at home (even if they claim to be 'allergenfree')

- Validity checking of 'allergen-free' claims (particularly on products made by individuals in their own home)

- How food allergy can be exacerbated (e.g. by exercise, alcohol)

- What voluntary labelling measures are undertaken by the food industry (for when people are travelling)

- Education for food manufacturers (about food allergy and intolerance, living with food allergy, dealing with and not dismissing people who have food intolerance etc.)

- Guidance for manufacturers on how to create an 'allergen-free' product (with mentoring from people who have already done it)

precautionary labelling disallowed. It is, however, interesting to note that patient groups and food allergic consumers themselves did not want this to occur.

The results of the stakeholder analysis should be interpreted with care. Firstly, the methodology applied in the analysis does not provide any information about whether people don't want information about any of these issues to be available. Secondly, it should be noted that the representatives of some of the key stakeholder groups were not included in the stakeholder analysis (e.g. schools, the media). Thirdly, the items on the communication issues list have been presented 'context-free'. For example, there is no information presented about wider implications (such as cost) of having segregated production lines. There is a need to be aware of the context surrounding each of the communication issues, and the practicalities involved in dealing with these issues.

When communicating the types of information identified in the stakeholder analysis, it is also important to consider how the information will be delivered and by whom. For example, not all allergic consumers need all the information delivered constantly, implying the need to target information through appropriate channels. Related to this, as stated previously, there is a possibility that increased communication about the various aspects of food allergy may result in increased perceived food allergy or food intolerance amongst the non-allergic general public. Care must be taken to utilize 
appropriate definitions (e.g. of food allergy and food intolerance) in communication, as well as providing a detailed and relevant symptomology if self-diagnosis is a potential unintended outcome of the communication activity. As far as industrial stakeholders, caterers and retailers are concerned, it is also important to differentiate between communication required as part of normal working and during product investigation, crisis, recall or product alert. In the case of the former, food-allergy information could be provided with food-safety and hygiene training. Future resources might be directed towards disseminating information about how much of the allergenic material is required for a reaction, how severe symptoms are (particularly in relation to dose), what self-testing kits are/will become available, and whether perceived food allergy is associated with any psychological conditions (e.g. stress, anxiety).

\section{Conclusions}

There is generally some consistency about the information needs of different stakeholder groups. But, some divergences, particularly in terms of differences between manufacturers and retailers, compared to allergic consumers and health professionals, have been identified. The former, in particular, required more information about clear guidelines for labelling practices, whereas the patients and health professionals required more information about symptomology, treatment and prevention. Although there was consensus about the basic communication needs across the different groups, these key differences between different stakeholders emerged in need for specific, more detailed information, indicating the need to develop differentiated communication strategies.

Regulators specifically need information from risk assessors regarding issues key to the implementation of an effective regulatory framework. This may need to be at a more detailed level of technicality than that required by other stakeholders (for example, consumers). However, communication from assessors to decision-makers (and vice-versa) should still be subject to the principle of transparency, which requires intelligibility to all external observers.

Retailers, manufacturers and caterers require information about the implications of mandatory labelling requirements and so forth. Retailers in particular are concerned about the effect of providing consumers with misleading information about specific products, and this may have implications for the introduction of standards.

Patient groups and health professionals were particularly concerned about broader public-health issues, as well as perceiving the need to develop information addressing the societal management of food allergy at different stages in the allergic patient's life. For these stakeholders, broader dissemination of information to the general (nonallergic) community was also a priority.

Whilst the stakeholder analysis effectively identified specific information needs of different stakeholder groups, the effectiveness of current communications strategies was not discussed. This issue will be the topic of further research in the InformAll project.

\section{Acknowledgement}

InformAll is a three-year, EU-funded project (QLRT-2001-02284), co-ordinated by Dr Clare Mills at the Institute of Food Research (Norwich Research Park, Colney, Norfolk, NR4 7UA, United Kingdom), that aims to develop communication strategies 
in the food-allergy area, which will promote the provision of visible, credible sources of information appropriate to different stakeholders including consumers, industry and regulators. Individual members of this workgroup form the list of authors of this paper.

\section{References}

Anderson, J.A., 1991. The clinical spectrum of food allergy in adults. Clinical and Experimental Allergy, 21 (Suppl. 1), 304-315.

Arborelius, E., 1996. Using doctor-patient communication to affect patients' lifestyles: theoretical and practical implications. Psychology and Health, 11 (6), 845-855.

Bock, S.A., Muñoz-Furlong, A. and Sampson, H.A., 2001. Fatalities due to anaphylactic reactions to foods. Journal of Allergy and Clinical Immunology, 107 (1), 191-193.

Bock, S.A. and Sampson, H.A., 1994. Food allergy in infancy. Pediatric Clinics of North America, 41 (5), 1047-1067.

Booth, D.A. and Knibb, R.C., 2000. What's the evidence that your problem comes from that food? Food Allergy and Intolerance, 1, 191-200.

Brugman, E., Meulmeester, J.F., Spee-Van der Wekke, A., et al., 1998. Prevalence of self-reported food hypersensitivity among school children in The Netherlands. European Journal of Clinical Nutrition, 52 (8), 577-581.

Davis, P.J., Smales, C.M. and James, D.C., 2001. How can thermal processing modify the antigenicity of proteins? Allergy, 56 (Suppl. 67), 56-60.

Eggesbo, M., Botten, G. and Stigum, H., 2001. Restricted diets in children with reactions to milk and egg perceived by their parents. Journal of Pediatrics, 139 (4), 583-587.

Eigenmann, P.A. and Zamora, S.A., 2002. An internet-based survey on the circumstances of food-induced reactions following the diagnosis of IgEmediated food allergy. Allergy, 57 (5), 449-453.

Fernández-Rivas, M. and Miles, S., 2004. Food allergies: clinical and psychosocial perspectives. In: Mills, E.N.C. and Shewry, P.R. eds. Plant food allergens. Blackwell, Oxford, 1-23.

Frewer, L.J. and Salter, B., in press. Societal trust in risk analysis: implications for the interface of risk assessment and risk management. In: Siegrist, M. ed. Risk management and public trust. Earthscan, London.

Gani, F., Pozzi, E., Crivellaro, M.A., et al., 2001. The role of patient training in the management of seasonal rhinitis and asthma: clinical implications. Allergy, 56 (1), 65-68.

Gilissen, L.J.W., 1998. Transgene-centred evaluation of genetically modified plants. In: De Vries, G.E. ed. Past, present and future considerations in risk assessment when using GMO's: [second international CCRO] workshop proceedings, Leeuwenhorst Congress Centre Noordwijkerhout, the Netherlands, March 5-6, 1998. CCRO, Bilthoven, 83-88.

Gilissen, L.J.W. and Nap, J.P., 1997. Assessment of allergenic potential of foods from genetically modified plants. CPRO-DLO, Wageningen.

Golin, C.E., DiMatteo, M.R. and Gelberg, L., 1996. The role of patient participation in the doctor visit: implications for adherence to diabetes care. Diabetes Care, 19 (10), 1153-1164. 
Gowland, M.H., 2002. Food allergen avoidance: risk assessment for life. Proceedings of the Nutrition Society, 61 (1), 39-43.

Hourihane, J.O., 2001a. Community management of severe allergies must be integrated and comprehensive, and must consist of more than just epinephrine. Allergy, 56 (11), 1023-1025.

Hourihane, J.O., 2001b. The threshold concept in food safety and its applicability to food allergy. Allergy, 56 (Suppl. 67), 86-90.

Joshi, P., Mofidi, S. and Sicherer, S.H., 2002. Interpretation of commercial food ingredient labels by parents of food-allergic children. Journal of Allergy and Clinical Immunology, 109 (6), 1019-1021.

Knibb, R.C., 2003. Parental knowledge and anxiety when taking their children to be food allergy tested. Proceedings of the British Psychological Society, 11 (1), 130.

Knibb, R.C., Armstrong, A., Booth, D.A., et al., 1999a. Psychological characteristics of people with perceived food intolerance in a community sample. Journal of Psychosomatic Research, 47 (6), 545-554.

Knibb, R.C., Booth, D.A., Platts, R., et al., 1999b. Episodic and semantic memory in accounts of food intolerance. Applied Cognitive Psychology, 13 (5), 451-464.

Knibb, R.C., Booth, D.A., Platts, R., et al., 2000. Consequences of perceived food intolerance for welfare, lifestyle and food choice practices, in a community sample. Psychology, Health and Medicine, 5 (4), 419-430.

McCabe, M., Lyons, R.A., Hodgson, P., et al., 2001. Management of peanut allergy. Lancet, 357 (9267), 1531-1532.

Meltzer, E.O., 2001. Quality of life in adults and children with allergic rhinitis. Journal of Allergy and Clinical Immunology, 108 (Suppl. 1), S45-S53.

Oehlschlager, S., Reece, P., Brown, A., et al., 2001. Food allergy: towards predictive testing for novel foods. Food Additives and Contaminants, 18 (12), 10991107.

Ong, L.M., De Haes, J.C., Hoos, A.M., et al., 1995. Doctor-patient communication: a review of the literature. Social Science and Medicine, 40 (7), 903-918.

Ortolani, C., Bruijnzeel-Koomen, C., Bengtsson, U., et al., 1999. Controversial aspects of adverse reactions to food: European Academy of Allergology and Clinical Immunology (EAACI) Reactions to Food Subcommittee. Allergy, 54 (1), 27-45.

Primeau, M.N., Kagan, R., Joseph, L., et al., 2000. The psychological burden of peanut allergy as perceived by adults with peanut allergy and the parents of peanut-allergic children. Clinical and Experimental Allergy, 30 (8), 11351143.

Pumphrey, R.S., 2000. Lessons for management of anaphylaxis from a study of fatal reactions. Clinical and Experimental Allergy, 30 (8), 1144-1150.

Rothman, A.J., Martino, S.C., Bedell, B.T., et al., 1999. The systematic influence of gain- and loss-framed messages on interest in and use of different types of health behaviour. Personality and Social Psychology Bulletin, 25 (11), 13551369.

Rothman, A.J. and Salovey, P., 1997. Shaping perceptions to motivate healthy behavior: the role of message framing. Psychological Bulletin, 121 (1), 3-19.

Rudeschko, O., Fahlbusch, B., Steurich, F., et al., 1998. Kiwi allergens and their cross-reactivity with birch, rye, timothy, and mugwort pollen. Journal of Investigational Allergology and Clinical Immunology, 8 (2), 78-84. 
Sampson, H.A., 2001. Immunological approaches to the treatment of food allergy. Pediatric Allergy and Immunology, 12 (Suppl. 14), 91-96.

Semper, H.M. and Knibb, R.C., in press. Stress in parents of severely food allergic children: does consulting a health professional influence stress levels? Proceedings of the British Psychological Society.

Sicherer, S.H., Noone, S.A. and Muñoz-Furlong, A., 2001. The impact of childhood food allergy on quality of life. Annals of Allergy, Asthma and Immunology, 87 (6), 461-464.

Sloan, A.E. and Powers, M.E., 1986. A perspective on popular perceptions of adverse reactions to foods. Journal of Allergy and Clinical Immunology, 78 (1 Pt. 2), 127-133.

Soler-Rivas, C. and Wichers, H.J., 2001. Impact of (bio)chemical and physical procedures on food allergen stability. Allergy, 56 (Suppl. 67), 52-55.

Taylor, S.L. and Hefle, S.L., 2001. Will genetically modified foods be allergenic? Journal of Allergy and Clinical Immunology, 107 (5), 765-771.

Wood, R.A., 2002. Food manufacturing and the allergic consumer: accidents waiting to happen. Journal of Allergy and Clinical Immunology, 109 (6), 920-922.

Woods, R.K., Stoney, R.M., Raven, J., et al., 2002. Reported adverse food reactions overestimate true food allergy in the community. European Journal of Clinical Nutrition, 56 (1), 31-36.

Young, E., Stoneham, M.D., Petruckevitch, A., et al., 1994. A population study of food intolerance. Lancet, 343 (8906), 1127-1130.

Yunginger, J.W., Sweeney, K.G., Sturner, W.Q., et al., 1988. Fatal food-induced anaphylaxis. JAMA, 260 (10), 1450-1452. 